\title{
Effects of Positive Psychology Interventions in Depressive Patients-A Randomized Control Study
}

\author{
Reinhard Pietrowsky*, Johannes Mikutta \\ Department of Clinical Psychology, University of Düsseldorf, Düsseldorf, Germany \\ Email: "R. Pietrowsky@hhu.de
}

Received September $26^{\text {th }}, 2012$; revised October $24^{\text {th }}, 2012$; accepted November $21^{\text {st }}, 2012$

\begin{abstract}
Effects of Positive Psychology (PP) have been shown in several studies to alleviate depressive symptoms in patients suffering from major depression or dysthymia when administered within psychotherapy. The present study served to test for the effects of two interventions from PP (best possible self, three good things) when practised by depressive patients for three weeks without any other concomitant psychotherapy. Seventeen depressive patients were randomly assigned to either the PP group or the control group. Patients in the PP group wrote down the best possible self for one week and then three good things for another two weeks. Patients in the control group wrote down images of the future of mankind for one week and early memories for two weeks. Prior to the intervention and again after it had finished, depressive symptoms, satisfaction with life, positive and negative affect, optimism, and resilience were assessed. While in both groups of patients well-being and resilience increased and depressive symptoms declined, the decline of depressive symptoms and the increase of positive affect and resilience were more pronounced in the PP group. The results support the notion that even a short intervention using PP alone alleviates depressive symptoms and increases well-being. Although the effects were of marginal significance, this may be attributed to the relatively small sample size. Likewise, the use of an Intent-to-Treat analysis may have affected the PP group more than the control group, indicating an underestimation of the potency of PP in the present study.
\end{abstract}

Keywords: Positive Psychology; Depression; Randomised Control Trial; Well-Being; Resilience

\section{Introduction}

Positive Psychology (PP) can be regarded as that discipline in psychology that focuses on positive experiences, positive emotions, positive personality traits and positive social interacttions. PP has the aim of extending the present focus of psychotherapy on negative aspects of human functioning to aspects that lead to happiness and a successful life. Seligman and Csiksentmihalyi (2000: p. 5) define PP as follows: "The aim of positive psychology is to begin to catalyze a change in the focus of psychology from preoccupation only with repairing the worst things in life to also building positive qualities". Thus, the principle "fix what's wrong" should be replaced by the principle "build what's strong" (Duckworth, Steen, \& Seligman, 2005).

\section{Target Factors of Positive Psychology}

Main variables on which PP focuses are happiness, subjective well-being, and positive affect. These variables overlap to some extent and each is also a component of the others. Happiness can be regarded as the main goal of positive psychology and thus of psychological or psychotherapeutic interventions. Happiness is regarded as comprising self-experienced satisfaction with life and the relative amounts of positive and negative affect. It is close to the concept of subjective well-being (SWB). High SWB also arises from the experience of more positive than negative affect and a satisfaction with life (Andrews \&

${ }^{*}$ Corresponding author.
Whitey, 1984). According to Diener, Suh, Lucas and Smith (1999), SWB can be the result of bottom-up and top-down processes, i.e., a cumulation of singular events of happiness or an attitude of the subject to experience events in a positive way, respectively. In addition, teleological theories assume that SWB is the result of the attainment of a specific state or an important personal goal. In contrast, other theories assume that happiness is not the goal of human activity but results from specific actions, as assumed by the flow concept (Csikszentmihalyi, 1990).

As mentioned, the ratio of positive and negative affect is a main constituent of SWB and thus happiness. Evidently, the preponderance of positive affect over negative affect is related to more SWB and happiness. Recent theories assume that positive and negative affect are not merely the poles of a single (bipolar) dimension, but are independent factors (Watson \& Clark, 1997). Thus, the experience of positive affect may not merely indicate a lack of negative affect. Rather, both may be concurrent, i.e., a person may experience high positive affect and, concomitantly, high negative affect. Likewise, the reduction of negative affect, as in the treatment of depressive patients, may not automatically result in an increase of positive affect. On the other hand, there is some profound criticism of the assumption that positive and negative affect are independent factors (Green, Goldman, \& Salovey, 1993; Russel \& Carrol, 1999). This controversy may hint at the fact that in a short-term perspective there may be a high correlation between both (bipolarity), while in a long-term perspective they can be regarded as independent (Diener \& Emmons, 1984). Positive affect can 
induce a specific way of thinking, feeling and acting and thus facilitate SWB and happiness. As Lyubomirsky, King and Diener (2005) have shown, positive affect is related to personality factors such as optimism, self-efficacy, activity, flexibility, and a functional coping with stress. Thus, positive affect-in a long-term perspective - may be the result of personality factors like optimism and resilience.

Optimism is a capacity that fosters positive affect. It can be defined as expecting the best and that goals will be reached and dreams and hopes will come true. Optimism can be regarded as a disposition in terms of a personality trait (Scheier \& Carver, 1985) and as an attributional style (Buchanan \& Seligman, 1995). Optimism leads to a functional tracking of goals, which itself is an important predictor of satisfaction and the use of adaptive and problem-oriented coping strategies (Scheier \& Carver, 1992). A low or missing optimism can be regarded as an important factor to elicit a depression (Schueller \& Seligman, 2008).

Another factor that may contribute to happiness is gratefulness. Gratefulness means to consciously attend to the happy things of one's life, to appreciate them and to be thankful for them. By this means gratefulness is an important factor in improving SWB (Bryant, 1989). Gratefulness results from the understanding that positive things that happen to oneself have a cause, and this understanding can imbue the things one is doing or that happen to one with meaning (McCullough, 2002). Moreover, gratefulness is incompatible with the feeling of negative affect (McCullough, Emmons, \& Tsang, 2002). Gratefulness is thus an important factor that strengthens resilience, which by itself is a major determinant of well-being, satisfaction with life, and happiness.

\section{Positive Psychology Interventions}

Since the ratio of positive to negative affect, optimism, and gratefulness can be regarded as important factors for happiness and SWB, PP interventions thus are intended to induce positive affect and minimize negative affect and to enhance optimism and gratefulness in order to increase SWB and happiness. An intervention task used by PP to increase positive affect and optimism is the so-called "Best Possible Self" (BPS), in which the intent is to think of the future in a positive way and to believe that personal goals can be reached. This technique was introduced by King (2001) and is derived from expressive writing. In a study by Sheldon and Lyubomirsky (2006) practice of this task for six weeks led to more positive affect in psychology students compared to a control task. In a further study, Lyubomirsky, Dickerhoff, Boehm and Sheldon (2011) could demonstrate in a student sample that the BPS task also increased optimism when performed for eight weeks compared to a control task. Likewise, Peterson, Flink, Boersma and Linton (2010) could demonstrate that positive affect and optimism increased in a student sample following this task compared to a control task. Moreover, these authors showed that the increase in optimism was independent of the increase in positive affect. Tasks that are suitable to increase gratefulness are the "Counting one's blessings" (COB) and the "3 Good Things" (3GT). In the $\mathrm{COB}$, the participants are instructed to write down what they are thankful for. Emmons and McCullough (2003) showed that $\mathrm{COB}$ enhanced gratefulness, life satisfaction and optimism as compared to a control task. In the 3GT, subjects write down three things every evening that have gone well and why these things went well. In an internet-based randomized study, Seligman, Steen, Park and Peterson (2005) could demonstrate that the $3 \mathrm{GD}$ was capable of increasing happiness and reducing depressive symptoms in a one-week treatment. Likewise, a combination of $3 \mathrm{GT}$ and $\mathrm{COB}$ was shown to induce gratefulness and enhance life satisfaction and positive affect in teachers (Chan, 2010).

\section{Assessment of the Target Factors}

The target variables of PP such as SWB, positive and negative affect, and optimism can be assessed using specific questionnaires. Well established questionnaires, which were also used in the above-mentioned studies, are the Satisfaction with Life Scales (SWLS) (Diener, Emmons, Larsen, \& Griffin, 1985) used to assess satisfaction with life, the Positive and Negative Affect Schedule (PANAS) (Watson, Clark, \& Tellegen, 1988) used to assess positive and negative affect, and the Life Orientation Test (LOT) (Scheier, Carver, \& Bridges, 1994) used to assess optimism. These three variables are indicators of SWB. To our knowledge, there is no established questionnaire to assess gratefulness. Accordingly, gratefulness was assessed by the feeling of relatedness to other people (Emmons \& McCullough, 2003) or derived from positive affect or feelings of happiness (Seligman et al., 2005). In our opinion, resilience as a personality feature that describes the "acceptance of the self and life" covers some aspects of gratefulness. Thus, we decided to assess resilience, which has rarely been assessed in PP research, as a further indicator of PP effects, mainly on personal competence, acceptance and also gratefulness.

\section{Rationale of the Present Study}

While there are numerous studies that showed effects of PP interventions in non-clinical samples (e.g., Sin \& Lyubomirsky, 2009), only a few studies have investigated the effects of PP in clinical samples of depressive patients. While in these studies the PP interventions have been rather extensive and in the form of an individualized therapy (e.g., Seligman, Rashid, \& Parks, 2006), the present study served to investigate the effects of a short PP intervention in a group of depressive patients, who were provided only with instructions concerning the PP tasks. Thus, interference with effects from current psychotherapy or unspecific therapeutic effects was avoided. In a randomized manner the patients received either two PP tasks (BPS, 3GT) or two control tasks for a three week period. We expected the PP tasks to enhance satisfaction with life, the ratio of positive to negative affect, optimism and gratefulness (as assessed by a resilience scale) and to reduce depression.

\section{Methods and Materials}

\section{Participants}

Seventeen depressive participants ( 8 male, 9 female) took part in the study. Patients were recruited from a larger sample of 43 participants who were on the waiting list for the psychotherapeutic outpatient clinic at the University of Düsseldorf, Germany. Inclusion criteria of this sample were a BDI-II score greater than 19. From this sample, 15 patients were excluded due to the exclusion criteria while 11 patients were not interested in participating in the study. Exclusion criteria were suicidal tendencies, comorbid psychiatric diseases, and start of 
psychotherapy during the course of the study. The remaining 17 patients were randomly assigned to either the experimental $(\mathrm{N}$ =9) group, which received a Positive Psychology treatment (PP) or the control group ( $\mathrm{CG} ; \mathrm{N}=8$ ), which received treatment as described below. Two patients of each group dropped out during the treatment, however their data were included in the analysis due to an Intend-To-Treat analysis (see below). Mean age was 43.75 years (SD: 8.84) in the PP group, years after 34.11 (SD: $8.43 ; \mathrm{t}(15)=2.57, p<.05$ ) in the control group. In each group 5 participants were under medication with antidepressants. Medication was stable over the duration of the study. Informed written consent was obtained from each participant. The study was approved by the ethics committee of the University of Düsseldorf.

\section{Design}

All participants underwent three sessions. In the first session the participants were informed about the study and the treatment they would receive and filled out the questionnaires for the pre-testing as well as the written informed consent. Then the first task (see below) was explained. This session took about one hour. In the second session one week later, which took also about an hour, the practise of the first task was discussed and the participants reported what they had written down in the first task. They were encouraged to continue this task during the next two weeks. Then the second task was explained and the time fixed for a short phone interview in one week. This phone call served for a short test of the practise of the second task. The third session took place two weeks after the second session (i.e. one week after the phone interview) and served to talk about the practise of the second task. Then the questionnaires for the post-measurement were filled out. This session took about 45 minutes.

\section{Interventions}

Participants who received the PP treatment did the BPS task as the first intervention for one week (from session 1 to session 2). Instructions for the BPS task were given according to Sheldon and Lyubomirsky (2006). Participants were instructed to think about their best possible self and to write down their thoughts and feelings about that. In detail, they were instructed that to think about the best possible self means that they should imagine their future when whatever happened was as good as possible. For example, they have worked hard and have been successful in realising all their goals. They should imagine they had realised all their life dreams and their own potential. In that case, they should describe the best possible way how things should happen in their life to guide them to make decisions in the present. Participants were instructed to take $30 \mathrm{~min}$ of the next day at a quiet place to think about their BPS and to write down their thoughts on a sheet of paper. These recordings should be read by them once again during the week.

In the second and third week, PP participants did the 3GT task. Instructions for this task were given according to Seligman et al. (2005). Participants were told that people dwell too much on things that go wrong and too little on things that go well in their life. Of course, sometimes it may be helpful to analyse things that went wrong to avoid mistakes. Nonetheless, people tend to think about bad things most of the time. A way to prevent this may be to increase our ability to think about the good things in our life. However, this is not easy, because we are usually not experienced in that. Thus, this ability takes time to practice. Therefore the participants were asked to take 10 minutes of time each evening for two weeks to write down in a diary three things that went well that day and why these things went well. The diary was given to the participants in session 2 and was requested to bring it with them for session 3 .

As controls for the BPS task, participants in the controls group were given the task of writing about the future of mankind in the first week. To parallel with the task in the PP group, the participants in the CG also had to think about the future of mankind for $30 \mathrm{~min}$ each day in a quiet place and to write down their thoughts. Their task to think about the future of mankind means that they should think that all things will go well for mankind. People have worked hard and have been successful in attaining their goals. This should be seen as a realisation of their dreams and the potential of mankind. They should imagine the way how things could happen in the future to help the people and how this would affect their decisions in the present. This instruction also served to encourage the participants to think about good possible things, but in contrast to the BPS task, not with the focus on the own person and the self.

To control for the 3GT task, participants in the CG were requested to think about early memories. As a parallel with the task in the PP group, they were instructed to think about early memories and write them down in a diary for $10 \mathrm{~min}$ each evening for the following two weeks. They were to bring the diary with them in the third session.

\section{Measures}

Depression was assessed using the Beck Depressions Inventory, 2nd edition (BDI-II) (Beck, Steer, \& Brown, 1996; German version by Hautzinger, Keller, \& Kühner, 2006). The BDI-II is a standardized and widely used self-response questionnaire to assess depressive symptoms. Depressive symptoms during the last two weeks are assessed by 21 items with statements reflecting different degrees of agreement with an item, ranging from full disagreement (0) to full agreement (3). Sum scores $<13$ indicate no depression, $14-19$ indicates a mild depression, 20 - 29 indicates a moderate depression, and a sum score $>30$ indicates a severe depression.

Satisfaction with life was assessed by the Satisfaction with Life Scales (SWLS) (Diener et al., 1985; German version by Schumacher, Klaiberg, \& Brähler, 2003). The SWLS is a selfresponse questionnaire consisting of five statements (e.g., "I am satisfied with my life") to which the participant has to agree or disagree according to 7 alternatives ranging from full agreement to full disagreement. The scores are added to a sum score. Higher sum scores indicate a greater satisfaction with life, with a score of 20 indicating a neutral value. Thus, scores higher 20 indicate satisfaction with life, while scores lower 20 indicate dissatisfaction with life. The reliability of the SWLS is Cronbach's $\alpha=.87$ and the discriminative validity is given to positive and negative affect as well as to optimisms (Lucas, Diener, \& Suh, 1996).

Positive and negative affect were assessed using the Positive and Negative Affect Schedule (PANAS) (Watson et al., 1988; German version by Krohne, Egloff, Kohlmann, \& Tausch, 1996). The PANAS is also a self-response questionnaire, consisting of 20 adjectives, 10 for positive affect and 10 for negative affect (e.g., enthusiastic, inspired, irritable, distressed), to 
which the participant has to agree or not agree if the respective adjective describes his feeling during the last days. Answers are given to five alternatives ranging from full disagreement to full agreement. The ratings on each subscale (positive affect, negative affect) are added to a sum score with higher values representing higher positive or higher negative affect, respectively. The reliability (Cronbach's $\alpha$ ) is .88 for the positive affect-scale and .85 for the negative affect-scale (Krohne et al., 1996). External validity was shown by comparisons with reports on emotionality.

Optimism and pessimism were assessed using the Life Orientation Test-Revised (LOT-R) (Scheier, Carver, \& Bridges, 1994; German version by Glaesmer, Hoyer, Klotsche, \& Herzberg, 2008). The self-response questionnaire consists of 10 items (statements), of which three items measure optimism (e.g., I see my future always optimistic), three measure pessimism (e.g., I do not expect that something good will happen to me), and four are filler items. Answers to the statements are given to five alternatives ranging from full disagreement to full agreement, scored from 0 to 4 . The scores of the three items for optimism and the three items for pessimism are added, resulting in sum scores for optimism and pessimism, respectively. Higher scores indicate greater optimism or pessimism. Based on a factor analysis, it was shown that optimism and pessimism as assessed by the LOT-R are not opponent poles of one dimension but are independent factors, i.e., a person may have at once a low optimism and low pessimism or a high optimism and a high pessimism (Glaesmer et al., 2008). Reliability (Cronbach's $\alpha$ ) for the German version is .69 for optimism and .68 for pessimism. External validity is given by positive correlations to the concept of self-mastery and negative correlations to anxiety (Scheier et al., 1994).

Resilience was assessed using a short version (RS-11) of the Resilience Scale (RS) (Wagnild \& Young, 1993; German version by Schumacher, Leppert, Gunzelmann, Strauß, \& Brähler, 2005). It consists of 11 statements (e.g., If I have plans, I pursue them; Usually I can regard a situation from several perspectives) to which agreement in general is rated on a 7-point Likert scale $(1=$ full disagreement, $7=$ full agreement $)$. The scores of the 11 items are added, resulting in a sum score, with high scores indicating strong resilience. Reliability of the German version is good (Cronbachs's $\alpha=.91$ ) and validity is given by high positive correlations to self-efficacy (Schumacher et al., 2005).

\section{Statistical Analysis}

Data were analysed according to an Intention-to-Treat analysis, i.e., the data from subjects who refused to start with the treatment or that dropped out during the intervention period were also taken into consideration. Accordingly, the data from those participants were treated following a "last observation carried forward" (LOCF) protocol with the pre-measures also taken for the post-measure. This procedure is rather conservative and implies that no improvement has taken place due to the intervention.

Statistical analysis was based on an analysis of variance (ANOVA) with the between-group factor Treatment (PP vs. $\mathrm{CG}$ ) and the repeated measures factor Time (pre vs. post) for each of the dependent variables (depression, satisfaction with life, positive and negative affect, optimism, resilience). Prior to each ANOVA, a test for homogeneity of variances was applied.
A $p$-value $\leq .05$ was regarded as significant.

\section{Results}

Depression:

Depression ratings of both groups as assessed by the BDI-II were not significantly different prior to treatment (CG 28.25, PP 25.22; $\mathrm{t}(15)=0.36$, n.s.; Table 1). Depression ratings declined over the course of the study in both groups (Time: $\mathrm{F}(1,15)=10.29, p<.01)$. Although the Treatment $\times$ Time interaction in the ANOVA failed to reach statistical significance $(\mathrm{F}(1,15)=1.92$, n.s. $)$, depression declined more in the PP $(\mathrm{t}(8)$ $=2.88, p<.05)$ than in the $\mathrm{CG}(\mathrm{t}(7)=1.61 ; \mathrm{n} . \mathrm{s}$. $)$. There was no significant main effect for Treatment $(F(1,15)=1.75$, n.s.).

Satisfaction with Life:

Satisfaction with life was not affected by Time or by Treatment (Table 1).

Positive and negative affect:

Positive affect tended to be higher in the PP compared to the CG (24.67 vs. 19.65 ; Treatment: $\mathrm{F}(1,15)=3.04, p=.1)$. It also tended to increase during the study interval (pre: 21.24 , post: 23.32; Time: $\mathrm{F}(1,15)=3.58, p<.1$ ). The increase of positive affect was more pronounced in the PP than in the CG (Table 1), but this effect did not reach statistical significance (Treatment $\times$

Table 1. Means $( \pm \mathrm{SD})$ of the different dependent measures for depressive patients receiving either 3 weeks of Positive Psychology interventions (PP) or 3 weeks of a control treatment (CG).

\begin{tabular}{|c|c|c|c|}
\hline \multicolumn{3}{|c|}{ PP } & CG \\
\hline \multicolumn{4}{|c|}{ Depression } \\
\hline Pre & $25.22(2.99)$ & $28.25(9.19)$ & n.s. \\
\hline Post & $17.67(7.62)$ & $25.25(13.41)$ & n.s. \\
\hline \multicolumn{4}{|c|}{ Satisfaction with life } \\
\hline Pre & $16.44(4.77)$ & $15.88(4.32)$ & n.s. \\
\hline Post & $17.67(5.61)$ & $15.88(2.59)$ & n.s. \\
\hline \multicolumn{4}{|c|}{ Positive affect } \\
\hline Pre & $22.44(5.86)$ & $19.88(6.62)$ & n.s. \\
\hline Post & $26.89(6.35)$ & $19.75(5.92)$ & $p<.05$ \\
\hline \multicolumn{4}{|c|}{ Negative affect } \\
\hline Pre & $26.33(7.00)$ & $25.25(6.63)$ & n.s. \\
\hline Post & $21.89(5.26)$ & $24.50(8.12)$ & n.s. \\
\hline \multicolumn{4}{|c|}{ Optimism } \\
\hline Pre & $5.56(2.01)$ & $4.88(3.09)$ & n.s. \\
\hline Post & $5.89(2.42)$ & $4.25(3.00)$ & n.s. \\
\hline \multicolumn{4}{|c|}{ Pessimism } \\
\hline Pre & $5.56(1.67)$ & $6.25(2.12)$ & n.s. \\
\hline Post & $5.33(1.80)$ & $7.63(2.33)$ & $p<.05$ \\
\hline \multicolumn{4}{|c|}{ Resilience } \\
\hline Pre & $45.78(13.72)$ & $36.25(11.08)$ & n.s. \\
\hline Post & $51.22(10.21)$ & $36.88(10.23)$ & $p<.05$ \\
\hline
\end{tabular}


Time: $\mathrm{F}(1,15)=4.01, p<.1)$. Positive affect was significantly higher in the PP compared to the CG at the end of intervention $(26.89$ vs. $19.75 ; \mathrm{t}(15)=2.39, p<.05)$.

Negative Affect tended to decline across the study period (main effect Time: $\mathrm{F}(1,15)=4.34, p<.1$; Table 1). There was no significant effect of the intervention or a Treatment $\times$ Time interaction.

Optimism and Pessimism:

Optimism was not affected by Time or Treatment (Table 1). Pessimism was significantly higher in the CG compared to the PP group at the end of the intervention (7.63 vs. $5.33 ; \mathrm{t}(15)=$ $2.29, p<.05)$.

Resilience:

Resilience was generally higher in the PP compared to the CG (48.50 vs. 36.57 ; Treatment: $\mathrm{F}(1,15)=4.92 ; p<.05)$. It also increased during the study interval (pre: 41.29 , post: 44.47 ; Time: $\mathrm{F}(2,30)=4.70, p<.05)$. The Treatment $\times$ Time interaction tended toward statistical significance, indicating a more pronounced increase of resilience in the PP compared to the CG $(\mathrm{F}(1,15)=2.96, p=.1$; Table 1). This resulted in a significantly higher resilience in the PP group compared to the $\mathrm{CG}$ at the end of the intervention (51.22 vs. $36.88 ; \mathrm{t}(15)=2.89, p<.05)$.

\section{Discussion}

In the present study a short intervention of three weeks, not embedded in psychotherapy, was compared with a control intervention in depressive patients. The results show that PP was superior to the control intervention, i.e., all measures in the PP group improved, while this was not the case in the control group. Specifically, depression ratings, positive affect, and resilience increased markedly in the PP group compared to the control group, although these increases reached only marginal statistical significance. The fact that the differences between both groups after the three-week interventions were only marginally significant (i.e., $p<.1$ ) may be due to the small sample size of the present study, with nine depressive patients in the PP group and eight in the control group.

As expected, the depression ratings prior to the intervention did not differ significantly between the two groups. The depression ratings as assessed by the BDI-II were in the range of 19 to 45 , indicating moderate to severe depression. During the three-week intervention the depression ratings declined in both groups, but the decline was more pronounced in those patients receiving PP interventions. Although this difference was not displayed in a significant interaction in the ANOVA, subsequent t-tests were performed separately for each group; the t-tests confirmed a significant decline of depression ratings in the PP group but not in the control group. Following the intervention period, the mean depression ratings in the PP group were below the criterion for a moderate depression, while they remained above that score in the control group, which had started from a slightly higher level, it must be said. These results do not confirm a significant amelioration of depressive symptoms in patients with major depression as reported by Seligman et al. (2006). However, in their study, the patients received 14 therapy sessions in a personal instruction, while in the present investigation there was no concomitant therapy except for the explanation of the PP tasks.

Satisfaction with life as assessed by the SWLS was not affected by the intervention. Although the SWLS scores marginally increased following the PP intervention while remaining stable in the control group, this small effect did not reach statistical significance. On the one hand, this result is in contrast to the study reported by Seligman et al. (2006), who found a substantial improvement in SWLS ratings following a six-week PP intervention in mild to moderate depressive students. However, in their study the duration and intensity of the PP intervention was longer and greater than in the present study. On the other hand, the items of the SWLS describe a general satisfaction with life (i.e., "I have attained the main things that I wished for my life"), thus it is not too surprising that there are only small effects after the three weeks intervention in the present study, which may have been too short to alter satisfaction with general life goals.

Positive affect, as assessed by the PANAS, was improved by the PP intervention and even declined marginally in the control group. Since the PANAS assessed affect during the last few days, this questionnaire seems suitable to assess short-term changes in affect as caused by the intervention. As expected, three weeks of PP interventions enhanced positive affect in the depressive patients. This result is in line with other studies that showed that PP interventions enhanced positive affect (Peters et al., 2010; Sheldon \& Lyubomirsky, 2006). Negative affect declined marginally across the three weeks intervention in both groups. Thus, there was no specific effect of PP on negative affect compared to the control intervention.

Contrary to our expectation, optimism was not affected by the intervention. Although the statements of the LOT-R describe general appraisals of a person and the own life (i.e., "I see my future always optimistically"), we expected that these appraisals could be changed by the PP interventions. Especially the technique of the best possible self was expected to increase optimism due to the optimistic beliefs that are supposed to be evoked by that intervention. Accordingly, a number of previous studies did obtain positive effects of the BPS and an enhancement of optimism (Peters et al., 2010; Sheldon \& Lyubomirsky, 2006). Pessimism as assessed by the LOT-R was significantly higher in the control group at the end of the intervention period. Since the optimism and pessimism subscales of the LOT-R can be regarded as independent factors, it should have been possible that pessimism was reduced by the intervention irrespective of an effect on optimism. In fact, pessimism increased to a small extent in the control group, resulting in a significant difference at post measurement, while there was no effect on optimism. It may thus be concluded either that the PP interventions in the present study were too short or that the study group was too small (see below).

Resilience increased across the study with a more pronounced increase in the PP group. This effect was expected and may be predominantly caused by the " 3 good things" intervenetion, which is supposed to focus on the mastery of things and problems even in situations in which the patients see things that go wrong instead those that go well. This ability to focus on the good things, even when they are embedded in bad things, is a basic factor of resilience (and of PP) and also reflects gratefulness. The effects on resilience are in line with previous studies which showed positive effects of the COB and 3GT tasks on gratitude (Chan, 2010; Emmons \& McCullough, 2003; Seligman et al., 2005). In addition to effects on gratitude, the increase in resilience of course also hints at a higher resilience due to the PP interventions.

The patients in the present sample were recruited from the waiting list of a psychotherapeutic outpatient clinic. Since one 
inclusion criterion was a BDI-II score $>19$, they all had depression scores that indicated at least moderate depression $(>19$ on the BDI-II) prior to the intervention. On average, the control group had higher depression scores than the PP group, but this difference was not statistically significant. However, the higher depression score in the control group appears to be due to a single patient who had a BDI score of 45 prior to the intervention. With respect to clinical symptoms, four patients in each group shifted from moderate to mild depression during the course of the intervention, whereas the BDI scores increased in two patients from the control group. No such increase in the BDI score was observed in the PP group. These data also contain the two patients in each group whose pre-measures were also taken as post-measures and thus could not indicate any change.

Although the effects in the present study were of marginal significance, the relatively small sample size must be considered. Due to the large F-values in the ANOVAs for the respecttive Treatment $\times$ Time interactions, it can be assumed that the observed effects are strong and that given a larger sample of patients, they would have become statistically significant. Moreover, the PP intervention was of rather short duration (three weeks) and not guided by the therapist. In fact, the patients got only the instructions for the PP interventions and then practiced by themselves at home. In the second session, the experiences with the first intervention were discussed. Thus, the results indicate that even the instructions for the use of PP interventions with subsequent self-guided practice have remarkable effects. In contrast, in some other PP studies in which the PP interventions were included in a full and regular psychotherapy, effects of the same magnitude were observed (e.g., Seligman et al., 2006).

An additional factor that may account for the weak effects in the present study may be the use of an Intent-to-Treat analysis (ITT). Since two patients of each group dropped out during the intervention period, we used their pre-measures also as postmeasures, which is a conservative procedure, since it does not account for effects due to the intervention. Although the ITT was applied to two patients in each group, it cannot be supposed that their effects simply cancel out, since on our hypotheses we expected a more pronounced effect in the PP than in the CG. Thus, the ITT should affect the PP group more than the CG. This may be a further indication that the potency of PP was underestimated in the present study.

In summary, the present study showed weak but consistent effects of PP interventions in a sample of patients with moderate depression. These effects are of particular relevance since the patients received no other form of psychotherapy during or prior to the intervention. Thus, the positive effects on depressive symptoms, positive affect and resilience can be attributed only to the self-guided PP interventions of a short duration of three weeks. The results thus add to the increasing evidence for the positive and helpful effects of Positive Psychology in the treatment of different forms of psychological disturbances, including depression, and they show that PP interventions can be effective even without a concomitant psychotherapy.

\section{Acknowledgements}

We thank Helen-Rose Cleveland for language editing of the manuscript.

Financial disclosures: The authors have no conflict of interest to declare.

\section{REFERENCES}

Andrews, F. M., \& Whitey, S. B. (1984). Social indicators of wellbeing: America's perception of life quality. New York: Plenum Press.

Beck, A. T., Steer, R. A., \& Brown, G. K. (1996). Beck depression inventory (2nd ed.). New York: Guilford Press.

Bryant, F. B. (1989). A four-factor model of perceived control: Avoiding, coping, obtaining, and savouring. Journal of Personality, 57, 773-797. doi:10.1111/j.1467-6494.1989.tb00494.x

Buchanan, G., \& Seligman, M. E. P. (1995). Explanatory style. Hillsdale, NJ: Lawrence Erlbaum Associates.

Chan, D. W. (2010). Gratitude, gratitude intervention and subjective well-being among Chinese school teachers in Hong Kong. Educational Psychology, 30, 139-153. doi:10.1080/01443410903493934

Csikszentmihalyi, M. (1990). Flow: The psychology of optimal experience. New York: Harper and Row.

Diener, E., \& Emmons, R. A. (1984). The independence of positive and negative affect. Journal of Personality and Social Psychology, 47, 1105-1117. doi:10.1037/0022-3514.47.5.1105

Diener, E., Emmons, R. A., Larsen, R. J., \& Griffin, S. (1985). The satisfaction with life scale. Journal of Assessment, 49, 71-75.

Diener, E., Suh, E. M., Lucas, R. E., \& Smith, H. L. (1999). Subjective well-being: Three decades of progress. Psychological Bulletin, 125, 276-302. doi:10.1037/0033-2909.125.2.276

Duckworth, L. A., Steen, T. A., \& Seligman, M. E. P. (2005). Positive psychology in clinical practice. Annual Review of Clinical Psychology, 1, 629-651. doi:10.1146/annurev.clinpsy.1.102803.144154

Emmons, R. A., \& McCullough, M. E. (2003). Counting blessings versus burdens: An experimental investigation of gratitude and subjective well-being in daily life. Journal of Personality and Social Psychology, 84, 377-389. doi:10.1037/0022-3514.84.2.377

Glaesmer, J., Hoyer, J., Klotsche, J., \& Herzberg, P. Y. (2008). Die deutsche version des Life-Orientation-Tests (LOT-R) zum dispositionellen Optimismus und Pessimismus. Zeitschrift für Gesundheitspsychologie, 16, 26-31. doi:10.1026/0943-8149.16.1.26

Green, D. P., Goldman, S. L., \& Salovey, P. (1993). Measurement error masks bipolarity in affect ratings. Journal of Personality and Social Psychology, 64, 1029-1041. doi:10.1037/0022-3514.64.6.1029

Hautzinger, M., Keller, F., \& Kühner, C. (2006). BDI-II. Beck depressions inventar revision-Manual. Frankfurt: Harcourt Test Services.

King, L. A. (2001). The health benefits of writing about life goals. Personality and Social Psychology Bulletin, 27, 798-807. doi: $10.1177 / 0146167201277003$

Krohne, H. W., Egloff, B., Kohlmann, C. W., \& Tausch, A. (1996). Untersuchungen mit einer deutschen Version der Positive and Negative Affect Schedule (PANAS). Diagnostica, 42, 139-156.

Lucas, R. E., Diener, E., \& Suh, E. M. (1996). Disciminant validity of well-being measures. Journal of Personality and Social Psychology, 71, 616-628. doi:10.1037/0022-3514.71.3.616

Lyubomirsky, S., Dickerhoof, R., Boehm, J. K., \& Sheldon, K. M. (2011). Becoming happier takes both a will and a proper way: Two experimental longitudinal interventions to boost well-being. Emotion, 11, 391-402. doi:10.1037/a0022575

Lyubomirsky, S., King, L. A., \& Diener, E. (2005). The benefits of frequent positive affect: Does happiness lead to success? Psychological Bulletin, 131, 803-855. doi:10.1037/0033-2909.131.6.803

McCullough, M. E. (2002). Savoring life, past and present: Explaining what hope and gratitude share in common. Psychological Inquiry, 13, 202-204.

McCullough, M. E., Emmons, R. A., \& Tsang, J. (2002). The grateful disposition: A conceptual and empirical topography. Journal of Personality and Social Psychology, 82, 112-127. doi: $10.1037 / 0022-3514.82 .1 .112$

Peterson, M. L., Flink, I. K., Boersma, K., \& Linton, S. J. (2010). Manipulating optimism: Can imagining a best possible self be used to increase positive future expectancies? The Journal of Positive Psychology, 5, 204-211. doi:10.1080/17439761003790963 


\section{R. PIETROWSKY, J. MIKUTTA}

Russel, J. A., \& Carrol, J. M. (1999). On the bipolarity of positive and negative affect. Psychological Bulletin, 125, 3-30. doi:10.1037/0033-2909.125.1.3

Scheier, M. F., \& Carver, C. S. (1985). Optimism, coping, and health: Assessment and implications of generalized outcome expectancies. Health Psychology, 4, 219-247. doi:10.1037/0278-6133.4.3.219

Scheier, M. F., \& Carver, C. S. (1992). Effects of optimism on psychological and physical well-being: Theoretical overview and empirical update. Cognitive Therapy and Research, 16, 201-228. doi:10.1007/BF01173489

Scheier, M. F., Carver, C. S., \& Bridges, M. (1994). Distinguishing optimism from neuroticism (and trait anxiety, self-mastery, and self-esteem): A re-evaluation of the Life Orientation Test. Journal of Personality and Social Psychology, 67, 1063-1078. doi:10.1037/0022-3514.67.6.1063

Schueller, S. M., \& Seligman, M. E. P. (2008). Optimism and pessimism. In K. S., Dobson, \& D. J. A., Dozois (Eds.), Risk factors in depression (pp. 171-194). Oxford: Elsevier/Academic Press. doi:10.1016/B978-0-08-045078-0.00008-3

Schumacher, J., Klaiberg, A., \& Brähler, E. (2003). Diagnostische Verfahren zur Lebensqualität und Wohlbefinden. Göttingen: Hogrefe.

Schumacher, J., Leppert, K., Gunzelmann, T., Strauß, B., \& Brähler, E. (2005). Die Resilienzskala-Ein Fragebogen zur Erfassung der psychischen Widerstandsfähigkeit als Personenmerkmal. Zeitschrift für Klinische Psychologie, Psychiatrie und Psychotherapie, 53, 16-39.

Seligman, M. E. P., \& Csiksentmihalyi, M. (2000). Positive psychology:
An introduction. American Psychologist, 55, 5-14.

doi:10.1037/0003-066X.55.1.5

Seligman, M. E. P., Rashid, T., \& Parks, A. C. (2006). Positive psychotherapy. American Psychologist, 61, 774-788. doi:10.1037/0003-066X.61.8.774

Seligman, M. E. P., Steen, T., Park, N., \& Peterson, C. (2005). Positive psychology in progress: Empirical validation of interventions. American Psychologist, 60, 410-421.

doi:10.1037/0003-066X.60.5.410

Sheldon, K. M., \& Lyubomirsky, S. (2006). Achieving sustainable gains in happiness: Change your actions, nor your circumstances. Journal of Happiness Studies, 7, 55-86.

doi:10.1007/s10902-005-0868-8

Sin, N. L., \& Lyubomirsky, S. (2009). Enhancing well-being and alleviating depressive symptoms with positive psychology interventions: A practice-friendly meta-analysis. Journal of Clinical Psychology, 65, 467-487. doi: $10.1002 /$ jclp. 20593

Wagnild, G. M., \& Young, H. M. (1993). Development and psychometric evaluation of the resilience scale. Journal of Nursing Management, 1, 165-178.

Watson, D., \& Clark, L. A. (1997). Measurement and mismeasurement of mood: Recurrent and emergent issues. Journal of Personality and Social Psychology, 54, 1063-1070. doi:10.1037/0022-3514.54.6.1063

Watson, D., Clark, L. A., \& Tellegen, A. (1988). Development and validation of brief measures of positive and negative affect: The PANAS scales. Journal of Personality and Social Psychology, 54, 1063-1070. doi:10.1037/0022-3514.54.6.1063 